\title{
A concepção de docentes do curso de licenciatura em educação física: sobre o acesso e permanência da pessoa com deficiência no ensino superior
}

The conception of teachers of the licenciatura course in physical education: on the access and permanence of persons with disabilities in higher education

La concepción de docentes del curso de licenciatura en educación física: sobre el acceso y permanencia de la persona con discapacidad en la enseñanza superior

* Bárbara Andressa Mendonça de Rocha Mesquita Mestre pela Universidade Federal de Goiás, Goiânia, Goiás, Brasil. barbara_rocha10@hotmail.com - https://orcid.org/0000-0002-1917-3425

** Tadeu João Ribeiro Baptista

Professor doutor na Universidade Federal de Goiás, Goiânia, Goiás, Brasil. tadeujrbaptista@yahoo.com.br - http://orcid.org/0000-0001-5140-2032

Recebido em 20 de novembro de 2018

Aprovado em 12 de julho de 2019

Publicado em 12 de setembro de 2019

\section{RESUMO}

Este trabalho tem como objetivo geral analisar a concepção dos professores do Ensino Superior com relação ao acesso e à permanência das pessoas com deficiência no curso de licenciatura de uma faculdade de Educação Física do município de Goiânia. A abordagem escolhida para análise dos dados pesquisados é qualitativa, trata-se de um estudo descritivo de caráter transversal (TRIVIÑOS, 1987). Para a técnica de coleta de dados, foi utilizada uma entrevista semiestruturada aplicada a dois professores do curso de Licenciatura em Educação Física de uma universidade pública da cidade de Goiânia, que já lecionaram ou estejam lecionando alguma das disciplinas obrigatórias do curso para algum acadêmico com deficiência, como a baixa visão e a deficiência física $O$ estudo teve ênfase nas práticas pedagógicas dos docentes em relação à inclusão. Os dados demonstram que eles possuem consciência sobre a formação de estereótipos pela cultura e as situações de preconceito que as pessoas com deficiência sofreram e ainda sofrem na sociedade, inclusive no contexto educacional. Defendem que existem poucas ações, tanto por parte da universidade quanto dos professores, que correspondam a uma perspectiva inclusiva, excetuando-se a criação do núcleo de acessibilidade e algumas ações pedagógicas isoladas por parte dos professores. Portanto, apontam que são necessárias mudanças na cultura educacional da universidade capazes de promover o acesso e a 
permanência das pessoas com deficiência nessa instituição de Ensino Superior.

Palavras-chave: Ensino Superior; Pessoa com deficiência; Acesso; Permanência.

\begin{abstract}
This work aims to analyze the conception of Higher Education teachers regarding the access and permanence of people with disabilities in the degree course of a Physical Education college in the city of Goiânia. The approach chosen to analyze the data is qualitative, it is a descriptive cross-sectional study. For the data collection technique, a semi-structured interview was applied to two professors of the Licentiate degree in Physical Education of a public university in the city of Goiânia, who have already taught or are teaching some of the compulsory courses of the course for some academic with a disability, such as low vision and physical disability. The study emphasized the pedagogical practices of teachers in relation to inclusion. The data demonstrate that they are aware of the stereotyping of culture ad the situations of prejudice that ppeople with disabilities have suffered and still suffer in society, including in the educational context. . They argue that there are few actions, both on the part of the university and the teachers, that correspond to an inclusive perspective, except for the creation of the accessibility core and some isolated pedagogical actions by the teachers. Therefore, they point out that changes in the educational culture of the university are necessary to promote the access and permanence of people with disabilities in this institution of Higher Education.
\end{abstract}

Keywords: Higher Education; Disabled person; Access; Permanence.

\title{
RESUMEN
}

Este trabajo tiene como objetivo general analizar la concepción de los profesores de la Enseñanza Superior con relación al acceso ya la permanencia de las personas con discapacidad en el curso de licenciatura de una facultad de Educación Física del municipio de Goiânia. El enfoque escogido para el análisis de los datos investigados es cualitativo, se trata de un estudio descriptivo de carácter transversal (TRIVIÑOS, 1987). Para la técnica de recolección de datos, se utilizó una entrevista semiestructurada aplicada a dos profesores del curso de Licenciatura en Educación Física de una universidad pública de la ciudad de Goiânia, que ya han enseñado o están enseñando alguna de las disciplinas obligatorias del curso para algún académico con discapacidad, tales como baja visión y discapacidad física. Los datos demuestran que son conscientes de los estereotipos de cultura y las situaciones de prejuicio que las personas con discapacidades han sufrido y aún sufren en la sociedad, incluso en el contexto educativo. Defenden que existen pocas acciones, tanto por parte de la universidad y de los profesores, que correspondan a una perspectiva inclusiva, exceptuando la creación del núcleo de accesibilidad y algunas acciones pedagógicas aisladas por parte de los profesores. Por lo tanto, señalan que son necesarios cambios en la cultura educativa de la universidad capaces de promover el acceso y la permanencia de las personas con discapacidad en esa institución de Enseñanza Superior.

Palabras clave: Enseñanza Superior; Persona con discapacidad; Acceso; Permanencia. 


\section{Introdução}

A educação tem muito a ver com o tipo de cultura que nela se desenvolve, que ganha significado educativo através das práticas e dos códigos que se traduzem em processos educativos pelos conteúdos da cultura. Saviani (2011) define a educação como um fenômeno próprio dos seres humanos, ela é uma exigência para o processo do trabalho não material, o qual se trata da produção de ideias, conceitos, valores, símbolos, hábitos, atitudes e habilidades.

No entanto, estamos submetidos a uma educação voltada para o modo de produção capitalista, que tem como objetivo a transmissão de informações selecionadas pela ideologia dominante, que condiciona o indivíduo a uma consciência subordinada pautada na racionalidade. Logo, a universidade está subordinada a uma cultura educacional direcionada à eficiência, produção e preparação para o mercado de trabalho, de acordo com as normas estabelecidas pelo capital.

Consequentemente, essas condutas autoritárias limitam o acesso e permanência das pessoas com deficiência a qualquer nível de ensino, inclusive no Ensino Superior, pelo percurso histórico de marginalização, preconceito ${ }^{1}$ e estereótipos impostos socialmente sobre essa classe minoritária.

A universidade tem o papel de educar na construção de uma sociedade inclusiva e democrática. Os problemas sociais devem ser debatidos na universidade, que deve iniciar um diálogo de natureza ética em vez de limitar seu ensino apenas ao desenvolvimento de competências e habilidades. A universidade precisa formar pessoas críticas e reflexivas que questionem estereótipos impostos pela sociedade capitalista. Baptista (2013) afirma que "[...] a educação é um processo fundamental para a constituição humana, pois esta tarefa de consolidar uma consciência verdadeira pressupõe compromisso com uma consciência emancipada".

Nesse sentido, surge o seguinte problema: "Qual a concepção do professor universitário com relação ao acesso e permanência das pessoas com deficiência no Ensino Superior?"

\footnotetext{
1 O preconceito não é inato ao homem, é uma reação individual e diz respeito a um mecanismo desenvolvido pelo indivíduo para poder se defender de ameaças imaginárias, e assim é um falseamento da realidade, que o indivíduo foi impedido de enxergar. O indivíduo preconceituoso está propício a disseminar os estereótipos que são proporcionados pela cultura (CROCHÍK, 2006, p. 21-22).
} 
Nesse caminho, objetivamos analisar a concepção dos professores do Ensino Superior com relação ao acesso e permanência das pessoas com deficiência no curso de licenciatura de uma faculdade de Educação Física do município de Goiânia.

De acordo com o artigo $1^{\circ}$ da Convenção das Pessoas com Deficiência publicada em 2007 "pessoas com deficiência são aquelas que têm impedimentos de longo prazo de natureza física, mental, intelectual ou sensorial, os quais, em interação com diversas barreiras, podem obstruir sua participação plena e efetiva na sociedade em igualdades de condições com as demais pessoas" (BRASIL, 2012, p. 26).

A educação inclusiva surge nos anos 90 com o objetivo de englobar, em sala de aula regular, todos os alunos das minorias sociais. A educação inclusiva, para Crochík (2012) tem como objetivo permitir o enriquecimento de experiências pelos alunos, desenvolver a inteligência calcada na sensibilidade para a diferença, fazer crítica à competição e aos conceitos de gênio e de talento, buscar refletir sobre uma cooperação que seja independente dos interesses capitalistas e, por meio da crítica, condenar a redução da cultura a bens cultuais.

Talvez o mais importante a ser dito a respeito de se pensar a educação inclusiva pelas análises desenvolvidas pela teoria crítica é que ela permite um movimento social consciente dos limites de suas possibilidades nesta sociedade, sem abandonar a luta necessária por uma sociedade humana (CROCHÍK; CROCHÍK, 2011b, p. 121).

A universidade, sendo um espaço de produção do conhecimento e formação humana do indivíduo, tem o desafio de incluir essa diversidade e promover uma educação de qualidade aos acadêmicos que possuem qualquer tipo de deficiência. Assim, surge a necessidade de criar leis e normas que promovam a inclusão das pessoas com deficiência tanto no trabalho quanto no lazer e na educação.

Entre as normatizações e leis estão a Declaração de Salamanca (1994), Declaração sobre Educação para Todos (1990), Convenção das Pessoas com Deficiência (2007) e, mais recentemente, a Lei Brasileira de Inclusão da Pessoa com Deficiência, oㅜ 13.146, de 6 de julho de 2015, que estabelece os direitos da pessoa com deficiência no âmbito educacional, inclusive no Ensino Superior. No entanto, apesar das conquistas de inclusão dessas pessoas, os direitos adquiridos em lei não são plenamente respeitados na realidade social e educacional.

Deste modo, grande parte desse público encontra-se fora da universidade. Pois num universo de 1.510.336 alunos ingressantes, em universidades públicas e universidades 
privadas no Brasil, apenas 13.053 corresponde o ingresso ao ensino superior por pessoas com deficiência. Dentre esses $36,7 \%$ são deficientes físicos; $23,4 \%$ baixa visão e $12.9 \%$ são deficientes auditivos, portanto em 2015 os discentes com deficiência ingressante no Brasil correspondem a $0,4 \%$ de todos os cursos de graduação no país, segundo os dados do Censo da Educação Superior (MEC/Deep/Inep, 2018).

Tal fato se justifica por algumas ações desencadeadas por movimentos sociais que lutam pela implementação de políticas públicas visando adaptações na estrutura física das instituições, mudanças no currículo, efetivação de práticas pedagógicas inclusivas, além de mudanças atitudinais da comunidade acadêmica frente ao acesso e permanência das pessoas com deficiência ao Ensino Superior. Portanto, na atual conjuntura, essas pessoas ainda não são devidamente valorizadas e precisam lutar por seus direitos, entre eles a sua inserção no meio educacional, especialmente no Ensino Superior.

A ampliação do número de pessoas com deficiência no Ensino Superior passa pela efetivação de uma educação inclusiva, o que requer a criação de núcleos de acessibilidade que busquem o diálogo entre gestores, coordenadores, professores e alunos. Também é urgente minimizar as condutas preconceituosas e estereotipadas criadas pela cultura dominante e que são reproduzidas no contexto educacional. Umas das formas de iniciar essas mudanças no contexto universitário é a transformação na cultura educacional, visando formar cidadãos para além do mercado de trabalho, capazes de respeitar a diversidade, sem fazer distinção de classe, raça, crença, ideologia e padrões corporais.

Sendo assim, é fundamental que o professor do curso de licenciatura em educação física, sobremodo, nos aspectos vinculados aos temas da cultura corporal devem articular as suas ações metodológicas de uma maneira que seja possível apresentar uma conduta pedagógica crítica e acessível às diferentes formas de aprendizagem, direcionando o caminho do conhecimento de modo a incluir no processo educacional as pessoas com deficiência e elucidar para os demais alunos a relevância de uma universidade para todos, efetivando um dos elementos necessários para a educação inclusiva. Portanto, a ação da educação inclusiva não é meramente inserir o sujeito no contexto universitário, mas sim possibilitar que este aluno participe do cotidiano educacional, nas interações interpessoais e no processo de aprendizagem de todos os conteúdos. 


\section{Procedimentos metodológicos}

Trata-se de uma pesquisa descritiva de caráter transversal. O local escolhido para os estudos é um curso de licenciatura em Educação Física de uma universidade pública de Goiânia. Para a coleta de dados, a técnica utilizada foi a entrevista semiestruturada, aplicada para dois professores que lecionam disciplinas na área de humanas (TRIVIÑOS, 1987). O professor, necessariamente, precisa ter lecionado ou estar lecionando alguma disciplina obrigatória do curso para os acadêmicos com deficiência do curso de licenciatura em Educação Física.

Os critérios de inclusão para participação da pesquisa foram: professores do curso de Educação Física, professores que já lecionaram ou estejam lecionando durante o período da pesquisa uma disciplina obrigatória do curso para os alunos com algum tipo de deficiência, terem assinado o Termo de Consentimento Livre e Esclarecido, e professores que aceitaram responder às perguntas da pesquisa. $O$ critério de exclusão para participação na pesquisa são aqueles professores que nunca lecionaram aulas para nenhum dos alunos com deficiência da universidade e aqueles que não aceitaram responder às perguntas da pesquisa.

A análise de dados ocorreu de modo a organizar o que foi coletado pela entrevista semiestruturada com perguntas que visam coleta informações que tratam questões relacionadas ao tema investigado. Em seguida, realizou-se a união e interpretação dos dados, processo que apresentou a transcrição na íntegra da entrevista semiestruturada. A técnica escolhida para trabalhar os dados coletados foi a análise de conteúdo. De acordo com Bardin (2016), essa técnica de análise trabalha o discurso do emissor na busca da realidade por meio da mensagem. $O$ pesquisador selecionou os pontos mais significativos da entrevista com o objetivo de trazer material que dava subsídios ao objeto, sendo identificadas principalmente; a) as barreiras sociais; e b) a necessidade de mudanças na cultura universitária.

\section{As barreiras sociais vivenciadas pelas pessoas com deficiência que dificultam o acesso ao Ensino Superior}

Os professores entrevistados da universidade pública do município de Goiânia relataram ter tido a experiência de lecionar disciplina na área de Humanas para alguns alunos com deficiência no curso de Licenciatura em Educação Física. 
O entrevistado 1 possui três anos de docência na instituição de ensino pesquisada e, durante sua trajetória acadêmica, lecionou a disciplina Teoria do Esporte para uma aluna com deficiência motora. Já o entrevistado 2 possui 20 anos de docência nessa instituição de ensino e lecionou a disciplina Sujeito, Aprendizagem e Desenvolvimento para três alunos com deficiência, entre eles um aluno cadeirante, uma aluna com deficiência motora e de linguagem e uma aluna com baixa visão.

Desse modo, esse dado já aponta para o pequeno acesso das pessoas com deficiência nessa universidade no curso de Licenciatura em Educação Física, principalmente, pelo fato, de o entrevistado 2 possuir 20 anos de docência e ter lecionado apenas para três alunos com deficiência, de acordo com a informação dos professores, já que, frequentemente, em cursos de educação física, o corpo considerado ideal, é aparentemente, um critério de realização dessa graduação.

Através do relato do professor entrevistado 1, pode-se observar que as pessoas com deficiência ainda não têm grandes oportunidades de ingressar no Ensino Superior e necessitam lutar pelos seus direitos. Quando indagado sobre a existência de ações por parte da universidade para incluir as pessoas com deficiência, ele respondeu de forma clara e objetiva "Até o momento não" e acrescentou um comentário bastante crítico, condizente e oportuno.

A condição de opressão que o deficiente se encontra tece a universalidade com a mesma forma de dominação e expropriação que está instaurada nesse mundo. A luta é a mesma para os segmentos da classe trabalhadora e para todos os públicos que estão em condição de opressão (ENTREVISTADO 1, 17/Maio/2018).

Podemos perceber que o professor entrevistado é consciente da realidade social que a pessoa com deficiência enfrenta no seu cotidiano na busca pelos seus direitos enquanto cidadão, e demonstra saber que no contexto educacional essas barreiras também são reproduzidas. De acordo com Crochík, (2011a), a exclusão educacional das pessoas com deficiência é resultado da estrutura social em que vivemos e vai ao encontro da opinião do entrevistado 1, segundo a qual as pessoas com deficiência passam por situações preconceituosas, sendo que o preconceito é algo produzido pela sociedade.

As pessoas com deficiência passam e já passaram por situações preconceituosas. E como o preconceito é constitutivo dessa sociedade, acredito que vivenciarão ainda enfrentamentos como esses, enquanto a história não mudar seus fundamentos que produzem o preconceito como forma de racionalidade. (ENTREVISTADO 1, 17/Maio/2018). 
O preconceito incide na relação entre o indivíduo e a sociedade, que estabelece determinados padrões de comportamentos que devem ser seguidos, criando assim o que Crochík (2006) denomina de estereótipos. Um desses estereótipos, criado a partir de fatores ideológicos, econômicos, psíquicos e religiosos, é o que classifica as pessoas entre as que detêm a "força" e o "poder" e as que são consideradas "fracas" e "inferiores".

Os estereótipos são produzidos e fomentados por uma cultura que pede definições precisas, por meio de suas diversas agências: família, escola, meios de comunicação de massa etc.; nas quais a dúvida, como inimiga da ação, deve ser eliminada do pensamento e a certeza, perante a eficácia da ação, deve tomar lugar da verdade que aquela ação aponta: controle, quer da natureza, quer dos homens, para poder administrá-los (CROCHÍK, 2006, p. 22).

Portanto, o discurso social de eficiência empregado como forma de busca pelo progresso revela apenas a aparência dessa racionalidade, pois, por outro lado, essa padronização de comportamento impede que o sujeito exerça sua autonomia e o pensamento se reduz a fatos pré-moldados, servindo aos estereótipos como resposta para a dominação, mantendo o status quo.

A pessoa com deficiência é vítima do preconceito associado a diversos estereótipos, como incapaz, ineficiente, anormal, estranho, entre outros, que são produzidos e mantidos pela cultura. Deste modo, os estereótipos criados pela cultura perpetuam o preconceito e estão passíveis de ser reproduzidos nas diversas esferas sociais, como na família, na escola e no trabalho.

Ademais, de acordo com o entrevistado 2, o aluno cadeirante e o aluno com deficiência motora e de linguagem já concluíram o curso de graduação e o aluno com baixa visão ainda está cursando. Por outro lado, esse dado revela um fato interessante: mesmo que essa graduação envolva diversas expressões corporais de movimento, isso não impede que pessoas com deficiência física ou com baixa visão possam ter acesso a esse curso e concluí-lo com êxito.

O entrevistado 2 relatou que os alunos com deficiência física, além de terem concluído o curso de Educação Física, estão inseridos no mundo do trabalho e desempenham a função de professor como quaisquer outros, constatando que essas pessoas têm a possibilidade de ingressar em diversas áreas de conhecimento e do trabalho. 
Como vivemos numa sociedade em que o trabalho² é um elemento indispensável na formação humana e que o indivíduo só se constitui em sociedade, logo o trabalho é possibilidade de inclusão da pessoa com deficiência na sociedade e no seu reconhecimento enquanto ser humano. No entanto, existem contradições relacionadas ao trabalho na sociedade capitalista, pois o trabalho que deveria humanizar acaba alienando e produzindo sujeitos que não reconhecidos enquanto tais. Em contrapartida, mesmo identificando os processos contraditórios do trabalho na atual sociedade, as pessoas com deficiência possuem capacidades para serem inseridas no mercado de trabalho enquanto cidadãos de direito e representam a diversidade humana nos diversos espaços sociais.

\begin{abstract}
É por meio do trabalho que o ser humano se humaniza, se reconhece enquanto humano e se diferencia dos outros humanos, se percebendo parte de um todo, mas com diferenças. Quanto mais diferenças e mais respeito às diferenças, mais humanizado será o processo. Assim, não é possível pensar a inclusão sem a inserção da pessoa com deficiência no mundo do trabalho, já desde os processos escolares. No entanto, não se podem ignorar as contradições desse processo que se relacionam ao modo econômico da produção (CARLONI; REIS, 2017, p. 44).
\end{abstract}

Deste modo, é preciso compreender as contradições que estão postas na educação que forma para o trabalho. Pois a educação, que deveria formar para a emancipação e o reconhecimento das diferenças humanas, passam a contemplar o processo da lógica produtivista a fim de atender ao mercado de trabalho. Assim, produz as desigualdades sociais e desiguais oportunidades em diversos segmentos sociais, seja no trabalho, na economia, no lazer, na saúde e/ou na educação.

Portanto, a universidade deve refletir sobre um ensino mais crítico e reflexivo no processo formativo dos acadêmicos, no sentido de incluir as diferenças entre os sujeitos e não a mera transmissão de conteúdo para formar pessoas mecanizadas e aptas ao mercado de trabalho, sem o mínimo de pensamento crítico da realidade.

\footnotetext{
${ }^{2}$ O trabalho, na concepção de Marx (2010), se estabelece na relação entre homem e natureza, que constitui a consciência através da interação entre objetividade e subjetividade, as quais são materializadas na realidade e modificam a natureza ao longo da história. Chega-se ao ponto em que a objetivação da consciência com o objeto não produzirá reconhecimento do sujeito, de acordo com determinações históricas pelas condições materiais que esse sujeito vivencia na realidade. Essa objetivação da consciência é exteriorizada como alienação/estranhamento do homem, pois ele não se reconhece no objeto que produziu, pois, no modo de produção capitalista, a consciência está no capitalista que compra a força de trabalho do trabalhador. À medida que o trabalhador se submete a todas as condições do capital vendendo sua força de trabalho, o homem se reduz a uma máquina e se iguala a uma mercadoria. Marx afirma que "o trabalho é uma mercadoria" (MARX, 2010, p. 35).
} 
Mesmo com todas as contradições vivenciadas na sociedade capitalista, a busca por respeito à diversidade e pela igualdade de direitos deve ser praticada cotidianamente para que essas pessoas sejam, de fato, incluídas nos diversos espaços sociais, evitando os processos de marginalização e segregação de classes minoritárias, sejam elas negros, índios, mulheres e pessoas com deficiência.

Conceitua-se inclusão social como o processo pelo qual a sociedade se adapta para poder incluir, em seus sistemas sociais gerais, pessoas com necessidades especiais e, simultaneamente, estas se preparam para assumir papéis na sociedade. A inclusão social constitui então um processo bilateral no qual as pessoas, ainda excluídas, e a sociedade buscam, em parceria, equacionar problemas, decidir sobre soluções e efetivar a equiparação de oportunidades para todos (SASSAKI, 2006, p. 40).

Deste modo, a busca por uma inclusão social pode vir a acontecer através de um processo de democratização da educação que respeite a diversidade cultural e que tenha como objetivo o acesso de todos ao conhecimento e na formação de uma consciência crítica e mais emancipada.

A seguir, e assumindo o risco, gostaria de apresentar a minha concepção inicial de educação. Evidentemente não a assim chamada modelagem de pessoas, porque não temos o direito de modelar pessoas a partir do seu exterior; mas também não a mera transmissão de conhecimentos, cuja característica de coisa morta já foi mais do que destacada, mas a produção de uma consciência verdadeira (ADORNO, 2003, p. 141).

\section{A concepção dos professores universitários sobre as mudanças na cultura universitária para o acesso e permanência das pessoas com deficiência no Ensino Superior}

Os professores entrevistados dessa instituição pública reconhecem a importância de uma mudança na cultura educacional da universidade que promova a valorização e reconheça as potencialidades das pessoas com deficiência no Ensino Superior. Eles também apontam caminhos para a efetivação de uma educação mais democrática.

Eu acho que é preciso mexer na cultura educacional, pois ela é pouco aberta para a diversidade, porque ela baliza na questão da eficiência e da eficácia. Também é necessária uma mudança na didática universitária é fundamental no campo da formação educacional. Então mudanças amplas, profundas e de longo prazo pensada na diversidade não só para as pessoas com deficiência, mas para todos os alunos. (ENTREVISTADO 2, 23/Maio/2018).

Assim, como aponta o professor entrevistado, a educação na universidade, que deveria formar para a emancipação e para a humanização do homem, acaba se adequando ao modo de produção capitalista, criando uma cultura educacional pautada na eficiência, 
produção, eficácia e na padronização, desconsiderando a diversidade humana, logo a universidade nivela todos os alunos, os quais devem se adequar e buscar o patamar na produção de conhecimento, estabelecendo essa realidade universitária como meta qualitativa.

\begin{abstract}
A "qualidade", por sua vez, é definida como competência e excelência cujo critério é o "atendimento as necessidades de modernização da economia e desenvolvimento social"; e é medida pela produtividade, orientada por três critérios: quanto uma universidade produz, em quanto tempo produz e qual o custo do que produz (CHAUÍ, 2001, p. 184).
\end{abstract}

Contudo, a universidade deve quebrar esse paradigma que objetiva apenas a transmissão de conteúdo e a formação de pessoas para atuar no mercado de trabalho, necessita desenvolver sua função social de formação humana e, como tal, carece de aceitar a diversidade cultural e promover uma educação formativa profunda que possibilite aos acadêmicos a produção de uma consciência crítica, reflexiva e de tolerância à diversidade humana.

A educação inclusiva possui condições de promover um ensino para todos, que afasta a mera transmissão de conhecimento, mas possibilita experimentar diferentes formas de aprender, pois é uma educação aberta ao diálogo, tendo o objetivo de compreender e respeitar as necessidades de cada aluno. A educação inclusiva surge da ação de movimentos sociais em prol dos direitos civis das pessoas marginalizadas e segregadas na sociedade.

Portanto, mesmo sabendo das contradições sociais que envolvem a sociedade capitalista e as barreiras para promover uma educação inclusiva no contexto educacional, não são essas justificativas que farão cessar a busca pelo acesso e permanência da pessoa com deficiência no contexto escolar, inclusive no Ensino Superior. Como afirmam Marques, C. A. e Marques, L. P. (2003, p. 237), é função social da instituição de Ensino Superior "mostrar com clareza as contradições sociais e propor alternativas concretas, pois é nesse contexto que está a perspectiva de incluir".

Neste contexto, as universidades precisam se adequar para tornar o Ensino Superior um espaço democrático, justo e acessível a toda diversidade humana, seja religiosa, de gênero, cor, idade, raça e deficiência, através de uma educação inclusiva que seja praticada no cotidiano acadêmico por toda comunidade universitária e que envolva gestores, coordenadores, funcionários, professores, alunos e familiares. 
Pode-se observar, pelo relato do entrevistado 2, que ele possui uma visão mais crítica acerca da realidade acadêmica da universidade e entende que é necessário promover mudanças significativas no contexto universitário, tanto na cultura educacional como na didática, para garantir a inclusão da pessoa com deficiência no Ensino Superior. Portanto, essas mudanças podem acontecer a partir do momento em que a universidade estabelecer a educação inclusiva como norteadora das ações da comunidade universitária.

O entrevistado 2, quando indagado sobre quais ações a universidade poderia realizar para promover uma educação inclusiva no contexto universitário, trouxe elementos importantes que podem ser agregados no âmbito educacional para a concretização de uma educação mais inclusiva.

Deve haver uma mudança na ocupação dos espaços que permita, por exemplo, que o espaço contemple essa diversidade com espaços marcados e sinalizados. Aqui não tem sinalização para as pessoas com baixa visão, tem algumas dentro dos prédios, então eles não podem circular fora dos prédios. Talvez devesse ter um serviço de tutoria, a incorporação dos próprios deficientes no planejamento, pois são eles que sabem o que precisam. Aquisição de programas de computadores e outros equipamentos que ajudam na locomoção, identificação, estudo. Também é necessária uma mudança na didática universitária é fundamental no campo da formação educacional. Não é mudar pouco é mudar muito e ter um tempo maior para aprendizagem e para o registro. Os mobiliários não cabem corpos deficientes. Então destaco mudanças no mobiliário, na didática e na cultura universitária. A universidade pode elaborar cursos, semanas e eventos para tratar as questões didáticas e como lidar com a pessoa com deficiência. Isso desencadearia outras ações, se já em sala de aula enquadrasse essas mudanças didáticas (ENTREVISTADO 2).

A educação inclusiva considera as diferentes necessidades educacionais de cada aluno, propondo adaptações estruturais, pedagógicas, atitudinais, curriculares que favoreçam a aprendizagem e a autonomia dos sujeitos que são marginalizados e excluídos socialmente.

De acordo com Mazzotta (2005), a acessibilidade é um elemento fundamental para a efetivação de uma educação inclusiva, pois a acessibilidade não se restringe apenas a adaptações estruturais da instituição que facilitem o deslocamento da pessoa com deficiência. Claro que essa atitude é importante, mas não é suficiente. É preciso promover 
uma transformação nas relações sociais que possibilite a participação ativa das pessoas com deficiência no meio social.

Deste modo, podemos perceber que a entrevistada 2 traz elementos de uma acessibilidade de forma mais ampla, pois aponta para a importância de mudanças além do espaço físico, enquadradas no que chamamos de adaptações estruturais, enfatiza a importância de serviço de tutoria, que conhecemos no Ensino Superior como sendo de responsabilidade do professor de apoio pedagógico, reivindica o uso de tecnologias assistivas como computadores e programas que auxiliem na aprendizagem do aluno, destaca a importância de mudanças na didática exemplificando com a implementação de um tempo maior para a aprendizagem, o qual podemos relacionar com uma prática pedagógica inclusiva e com a formação continuada dos professores através de cursos e palestras. Esses elementos da acessibilidade favorecem na superação das diversas barreiras que impedem a autonomia e a independência da pessoa com deficiência nos espaços em que ela se encontra, assim concretizando uma educação inclusiva no contexto universitário.

Essas ações estão previstas em diversos documentos que respaldam o direito de ingressar no Ensino Superior, no entanto, o que se percebe são diversas instituições de ensino que não cumprem o seu papel social. Existe a Política Nacional de Educação Especial na Perspectiva da Educação Inclusiva, que definiu algumas ações para a Educação Especial por parte da universidade.

\footnotetext{
$\mathrm{Na}$ educação superior, a educação especial se efetiva por meio de ações que promovam o acesso, a permanência e a participação dos estudantes. Estas ações envolvem o planejamento e a organização de recursos e serviços para a promoção da acessibilidade arquitetônica, nas comunicações, nos sistemas de informação, nos materiais didáticos e pedagógicos, que devem ser disponibilizados nos processos seletivos e no desenvolvimento de todas as atividades que envolvam o ensino, a pesquisa e a extensão (BRASIL, 2008, p. 17).
}

Deste modo, as universidades necessitam desenvolver ações que favoreçam a valorização das pessoas com deficiência e que de fato eliminem as barreiras de acesso e permanência dessa classe minoritária, promovendo a acessibilidade em todos os seus aspectos, por meio de adaptações pedagógicas, atitudinais, curriculares e estruturais no espaço universitário.

De acordo com os relatos dos entrevistados 1 e 2 que lecionam na instituição de ensino no curso de Licenciatura em Educação Física, há diversas barreiras que 
transcendem as medidas de acessibilidade aqui mencionadas, dificultando o acesso e a permanência da pessoa com deficiência no Ensino Superior.

Existem muitas barreiras (ENTREVISTADO 1, 17/Maio/2018).

Todas as barreiras, existe pouca remoção de barreiras arquitetônicas. Aqui só tem rampas que não adianta. Aqui precisa de toda uma estrutura, com elevadores, portas mais largas, sanitários, rebaixamento de balcão, aqui não tem. O cadeirante tem que ficar olhando para cima. O mobiliário também precisa ser trocado, a universidade fica muito a dever. As barreiras atitudinais são as mais frequentes e muito mais ocultadas, às vezes não é aquele ódio explícito, mas há um preconceito do ignorar e ao mesmo tempo permissiva. (ENTREVISTADO 2, 23/Maio/2018).

Cabral (2013) expõe algumas legislações específicas da universidade que regulamentam as ações que garantem o acesso e a permanência da pessoa com deficiência na universidade, entre elas podemos descartar: o Aviso Circular $n^{\circ} 227$, de 08 de maio de 1996, do Ministério da Educação, que oferece aos reitores sugestões para favorecer o acesso da pessoa com deficiência no Ensino Superior; o Decreto 3.298, de 20 de dezembro de 1999, que dispõe no artigo 27 sobre a obrigatoriedade de adaptações para a realização de provas, apoio necessário para os alunos com deficiência, tempo adicional de prova e a execução de programas educacionais; a Portaria $n^{\circ} 3.284$, de 07 de novembro de 2003, que prevê requisitos básicos de acessibilidade, como mobilidade, utilização e equipamentos e instalações na instituição de ensino; o Plano Nacional de Educação sobre os direitos humanos de 2007, que expressa o desenvolvimento de políticas e ações afirmativas nas IES (Instituições de Ensino Superior) que tornem possíveis a inclusão, o acesso e a permanência das pessoas com deficiência no Ensino Superior.

Complementando os estudos de Cabral (2013), outro marco na legislação da educação inclusiva para as pessoas com deficiência está na recente Lei Brasileira de Inclusão da Pessoa com Deficiência, nํ⒔146, de 6 de julho de 2015, art. 27ํㅜ , que respalda o direito garantido de acesso à educação.

Art. 27 - A educação constitui direito da pessoa com deficiência, assegurados sistema educacional inclusivo em todos os níveis e aprendizado ao longo de toda a vida, de forma a alcançar o máximo desenvolvimento possível de seus talentos e habilidades físicas, sensoriais, intelectuais e sociais, segundo suas características, interesses e necessidades de aprendizagem (BRASIL, 2015, p. 7).

Conforme a legislação vigente, as instituições de ensino necessitam incluir todas as pessoas no espaço educacional, promovendo a aprendizagem significativa, processo que deve envolver toda a comunidade acadêmica, pois é importante ressaltar que cada ser 
humano possui singularidades e sua subjetividade deve ser considerada em todas as etapas.

Anache, Rovetto e Oliveira (2014) ressaltam que não podemos acreditar que apenas com a efetivação das políticas públicas educacionais a inclusão estará assegurada no contexto educacional. As políticas públicas são apenas um dos elementos essenciais para assegurar e manter os alunos com necessidades educacionais no Ensino Superior. Temos que avançar em outras questões, como a reformulação das práticas pedagógicas padronizadas, a eliminação da gestão arcaica das universidades, a flexibilização do currículo, a promoção de adaptações estruturais e atitudinais, além da utilização das tecnologias assistivas.

Apesar das diversas barreiras arquitetônicas e atitudinais relatadas nas entrevistas, o entrevistado 1 aponta a importância da criação de um núcleo de acessibilidade pela universidade.

Eu sei que existe um trabalho sendo realizado pelo núcleo de acessibilidade, que é uma iniciativa importante (ENTREVISTADO 1, 17/Maio/2018).

Uma das ações que favorecem a permanência do aluno com deficiência no Ensino Superior é a criação de um núcleo de acessibilidade pelas instituições de ensino.

Segundo o Decreto $n^{\circ} 7.611$, de 17 de novembro de 2011, no artigo $5^{\circ}$, § VII. ․, "[...] os núcleos de acessibilidade nas instituições federais de educação superior visam eliminar barreiras físicas, de comunicação e de informação que restringem a participação e o desenvolvimento acadêmico e social dos alunos com deficiência" (BRASIL, 2011, p.2).

Podemos perceber que as ações de um núcleo de acessibilidade são de extrema importância para assegurar as necessidades inclusivas e deveriam se estender a todas as universidades, sejam elas federais, estaduais ou privadas. É preciso trabalhar para que as metas do núcleo sejam desenvolvidas no contexto da educação universitária, a fim de que as pessoas com deficiência usufruam seu direito de acesso e permanência no Ensino Superior e que seja um local de comunicação e elaboração de estratégias acadêmica e institucional, para buscar uma educação de qualidade para as pessoas com necessidades educacionais especiais.

O entrevistado 2 também elucida algumas ações inclusivas por parte de alguns professores. 
http://dx.doi.org/10.5902/1984686X35737

O que eu percebo aqui são professores aqui e ali que têm conhecimento, têm alguma preocupação ou até algum incômodo. Porque o professor que fica incomodado às vezes com um aluno que tenha deficiência ou digamos ele apresenta um déficit no tempo de aprendizagem, no tempo de realização de tarefa e precisa de mais tempo, isso às vezes incomoda o professor e ele vai atrás disso. Os outros por uma questão humanista de compromisso com a inclusão também se interessam (ENTREVISTADO 2, 23/Maio/2018).

Essas ações são iniciativas que devem ser valorizadas e que merecem uma continuidade, no entanto, devemos ressaltar que a inclusão não se efetiva por movimentos isolados e independentes, devendo haver uma participação de todos os professores na busca por uma educação inclusiva que tenha como suporte uma prática pedagógica para a valorização das diferenças e para a autonomia intelectual.

A inclusão é um processo complexo que exige mudanças na organização educacional e o comprometimento por parte dos professores no processo de ensino-aprendizagem das diferentes formas subjetivas de aprendizagem, uma vez que as condições intelectuais, sensoriais e físicas dos alunos são bastante distintas, como explicam Lima e Masson (2018). Podemos afirmar que "somos todos iguais perante a lei, embora sejamos diferentes subjetivamente" (LIMA; MASSON, 2018, p. 56). Portanto, a universidade precisa ser um lugar no qual as diferenças subjetivas possam se expressar e se relacionar com seus pares de forma respeitosa, formando sujeitos que compreendem as diferenças subjetivas.

Para que esse processo de ensino-aprendizagem aconteça para todos em sala de aula de forma mais humanizada e qualitativa, Crochík (2011a), afirma que os professores precisam se afastar de uma prática pedagógica pautada na competição e voltada para a produtividade, a qual possui uma concepção de ensino arraigada no modelo de transmitir, verificar e registrar conteúdos. Portanto, o ensino para se tornar humanizado e qualitativa necessita que o professor reveja e direcione sua prática pedadogica para além da transmissão de conteúdos, visando desenvolver uma multiplicidade de saberes e de experiências educacionais.

O corpo docente da instituição deve estar preparado pedagogicamente para receber esses alunos. Esses professores são a base fundamental par assegurar a permanência dos alunos com deficiência na universidade, principalmente em um curso de licenciatura, que forma futuros professores, os quais também precisarão adotar uma postura pedagógica inclusiva em seus ambientes de trabalho para incluir as diferentes formas subjetivas de aprendizagem no contexto da escolar. Logo, a educação inclusiva é um ciclo contínuo que necessita ser praticado por todos os professores nas diferentes modalidades de ensino. 
http://dx.doi.org/10.5902/1984686X35737

[...] a organização do sistema educacional, na perspectiva inclusiva, aponta para um novo modelo de escola e, consequentemente, um novo modelo de formação docente, que requer um professor preparado para atuar em uma escola pautada na atenção à diversidade, para desenvolver sua prática pedagógica considerando diferentes modos de aprender e ensinar, contrários à cultura escolar tradicional, até então vigente, historicamente excludente, seletiva, pautada em um modelo de ensino homogeneizador (GIROTO; POKER; OMOTE, 2012, p. 12).

No entanto, Freitas, Delou e Castro, H. C. (2015) afirmam que o professor do Ensino Superior não está preparado para receber o aluno com deficiência, pois a formação inicial desses docentes é pautada pela padronização do ensino, com todos aprendendo ao mesmo tempo e de formas iguais, estabelecidas pelos padrões de normalidade. Deste modo, é preciso promover a formação continuada do docente, para que este consiga desempenhar sua prática pedagógica de forma mais humanizada e buscar adaptações que favoreçam no processo de ensino-aprendizagem dos alunos com deficiência no curso de graduação.

Assim, é importante que todos os professores, sem exceção, estejam conscientes de que são necessárias adaptações curriculares que possam ser desenvolvidas em sala de aula com total autonomia, estando entre elas: "[...] adaptação de objetivos; adaptação de conteúdos; adaptações do método de ensino e da organização didática; adaptação do processo de avaliação; adaptação na temporalidade do processo de ensino e aprendizagem" (PANSANATO; RODRIGUES; SILVA, 2016, p. 475).

Podemos constatar a necessidade de esforços pedagógicos do docente frente às adaptações curriculares para uma prática pedagógica inclusiva e de qualidade, por isso a importância desses professores terem uma formação continuada e que a universidade dê suporte para que essas ações continuadas se efetivem. Entretanto, deve-se ressalvar que a formação continuada por si só não efetiva uma prática pedagógica inclusiva, pois há professores que só se interessam por acumular certificados, sem nunca colocar em prática o que aprenderam na formação continuada. Esta só é efetiva na medida em que o professor, colocando em prática o conhecimento adquirido, se disponha a refletir e dialogar com a comunidade acadêmica sobre as necessidades educacionais dos alunos com deficiência.

A formação não se constrói por acumulação (de cursos, de conhecimentos ou de técnicas), mas sim através de um trabalho de reflexividade crítica sobre as práticas e de (re) construção permanente de uma identidade pessoal. Por isso é tão importante investir a pessoa e dar um estatuto ao saber da experiência. [...] Práticas de formação que tomem como referência as dimensões coletivas contribuem para a emancipação profissional e para a 
http://dx.doi.org/10.5902/1984686X35737

consolidação de uma profissão que é autônoma na produção dos seus saberes e dos seus valores. (NÓVOA, 1995, p. 25).

Deste modo, a formação mais humanista, crítica e reflexiva dará suporte pedagógico para que o professor possa mudar suas práticas diárias de acordo com as especificidades vivenciadas em classe, podendo o professor ter mais chances de efetivar uma educação inclusiva para todos os alunos. Crochík (2006) afirma que é importante desenvolver ações para combater o preconceito, contudo adverte que tais ações não o eliminam por completo, embora sem dúvida atenuem situações de preconceito ou discriminação.

Tanto os trabalhos de Sales, Moreira e Couto (2016) como os de Mendes e Bastos (2016) destacam as barreiras atitudinais que os professores criam por não saberem lidar com as dificuldades de aprendizagem dos alunos, nem questionar se de fato o aluno necessita de uma intervenção pedagógica diferenciada, perpetuando estereótipos influenciados pelo meio social, o que leva à segregação desses alunos. Vala e Monteiro (2002) afirmam que "[...] estereótipos são crenças que nos são transmitidas pela influência social, a partir dos meios de comunicação, tendo sua gênese no ambiente familiar, grupal e nas concepções de mundo e do contexto histórico e cultural de cada indivíduo" (apud SALES; MOREIRA; COUTO, 2016, p. 301).

Neste contexto, os professores não podem reproduzir os padrões de comportamento impostos pela sociedade no ambiente educacional, devendo, em vez disso, se livrar dessas amarras e desenvolver estratégias educacionais para construir uma prática pedagógica inclusiva eficaz que consiga suprir as demandas pedagógicas e realizar adaptações necessárias para a aprendizagem dos graduandos com necessidades educacionais especiais, para que seja criada assim uma boa convivência com os alunos.

\begin{abstract}
No contexto da docência, é fundamental que os professores compreendam que são sujeitos em permanente desenvolvimento, pois assim, construirão sua identidade profissional, influenciada por aspectos de natureza social e individual, podendo experimentar suas possibilidades e seus limites, ou seja, se envolverem com as situações de ensino capazes de favorecer a reflexão acerca das atividades pedagógicas no contexto de sua prática cotidiana e social. (BOLZAN; ISAIA; MACIEL, 2013 apud LANA; CASTRO, F. G. A. S; MARQUES, S. M. F., 2016, p. 74).
\end{abstract}

Assim, o professor, ao adotar uma nova postura pedagógica, a qual depende não apenas dele, mas das relações constituídas na universidade, diante da realidade social em que vivemos, considerando a sua relevância como um importante agente na construção de uma educação inclusiva comprometida com a democratização do ensino, que se afaste do totalitarismo e que se aproxime de uma educação que valorize a experiência e a reflexão 
dos alunos. Como aponta Leite e Acuna (2018, p. 12) "[...]a Educação só será inclusiva quando ocorrerem reformulações das práticas sociais e culturais com vistas a uma sociedade efetivamente democrática e equânime, em que a diferença não seja compreendida como desigualdade, mas sim, promotora de desenvolvimento humano". Deste modo, o professor, ao assumir a educação inclusiva como mediadora do processo de ensino-aprendizagem, tem a oportunidade de adaptar a sua prática pedagógica, possibilitando a todos os alunos almejar a autonomia intelectual, permitindo assegurar o acesso e a permanência da pessoa com deficiência no Ensino Superior e, quem sabe, tornar a sociedade mais humana.

\section{Conclusão}

Portanto, podemos identificar que, na concepção desses professores entrevistados no curso de Educação Física, as pessoas com deficiência têm potencialidades, como qualquer outra pessoa, para ingressar, permanecer e concluir esse curso de graduação. No entanto, deve haver mudanças significativas na busca por uma sociedade mais humanizada que minimize as condutas preconceituosas, a instituição de ensino necessita rejeitar uma cultura universitária pautada na transmissão de conhecimentos preestabelecidos e padronizados, promovendo uma cultura universitária que flexibilize o ensino e desenvolva adaptações físicas, curriculares, atitudinais e pedagógicas, para que esses estudantes possam ter a experiência e o direito de ingressar e permanecer no Ensino Superior de forma qualitativa e autônoma. Assim, a educação inclusiva é desafiadora, e a universidade é um lugar onde as ações sociais e a cidadania devem se manifestar com o intuito de desenvolver ações afirmativas a favor da inclusão, da diversidade, da democracia e, sobretudo, da autonomia do aluno com deficiência.

O professor é um dos sujeitos que possui o papel de assegurar a permanência desses acadêmicos, portanto deve de forma conjunta e não isolada buscar, através do diálogo, um ensino crítico-reflexivo que permita ao aluno experimentar a autonomia intelectual. Em contrapartida, precisamos salientar que não é de responsabilidade só dos professores promover a inclusão, deve haver o envolvimento de todo o grupo que compõe a universidade, dentre eles, coordenadores, gestores, familiares, alunos, professores e toda comunidade.

Neste contexto, a universidade, ao propor uma educação inclusiva que possa superar além dos obstáculos da aprendizagem, é importante na luta por uma sociedade mais justa, 
mesmo sabendo das dificuldades encontradas da educação atual. Assim, o ambiente educacional reflete as contradições sociais, que não podem ser negadas, mas necessitam ser discutidas com o intuito de formar sujeitos críticos capazes de respeitar a diversidade e se opor a qualquer tipo de opressão direcionada aos seres humanos, possibilitando às pessoas com deficiência melhores oportunidades de acesso e permanência para concluir um curso de graduação no Ensino Superior.

\section{Referências}

ADORNO, Theodor W. Educação para quê? In: Educação e Emancipação. Tradução: Wolfgang Leo Maar. $3^{\circ}$ Ed. São Paulo: Paz e Terra. Tradução: Wolfgang Leo Maar, 2003.

ANACHE, Alexandra Ayach; ROVETTO, Sabrina Stella Maris; OLIVEIRA, Regiane Alves. Desafios da implementação do atendimento educacional especializado no Ensino Superior. Revista Educação Especial, Santa Maria, v. 27, n. 49, p. 299-312, maio/ago., $2014 . \quad$ Disponível em: https://periodicos.ufsm.br/educacaoespecial/article/view/9037. Acesso em: 9 maio 2018.

BARDIN, Laurence. Análise de conteúdo. São Paulo: Edições 70, 2016.

BRASIL. Declaração de Salamanca e Linha de Ação sobre Necessidades Educativas Especiais. Brasília: Coordenadoria Nacional para Integração da Pessoa Portadora de Deficiência, 1994.

BRASIL. Convenção sobre os Direitos das Pessoas com Deficiência, 2007. Brasília, 2012. Disponível em: http://www.pessoacomdeficiencia.gov.br/app/sites/default/files/publicacoes/convenca opessoascomdeficiencia.pdf. Acesso em: 07 Jul. 2018.

BRASIL. Decreto $n^{\circ} \mathbf{7 . 6 1 1}$, de 17 de Novembro de 2011. Dispõe sobre a educação especial, o atendimento educacional especializado e dá outras providências. Brasília, 2011.

BRASIL. Lei № 13.146, de 6 de julho de 2015. Lei Brasileira de Inclusão da Pessoa com Deficiência. Estatuto da Pessoa com Deficiência. Diário Oficial da União - Seção $1-7 / 7 / 2015$.

BRASIL. Ministério da Educação. Política Nacional de Educação Especial na Perspectiva da educação Inclusiva, 2007. Disponível em: http://portal.mec.gov.br/index.php?option=com_docman\&view=download\&alias=1669 0-politica-nacional-de-educacao-especial-na-perspectiva-da-educacao-inclusiva05122014\&ltemid=30192. Acesso em: 07 jul. 2018. 
BRASIL. Instituto Nacional de Estudos e Pesquisas Educacionais Anísio Teixeira. Resumo técnico: Censo da Educação Superior, 2015. Brasília: Instituto Nacional de Estudos e Pesquisas Educacionais Anísio Teixeira, 2018.

CABRAL, Leonardo Santos Amâncio. Orientação acadêmica e profissional de estudantes universitários com deficiência: perspectivas internacionais. Tese (Doutorado em Educação Especial) - Centro de Educação e Ciências Humanas da Universidade Federal de São Carlos. São Paulo: São Carlos, 2013.

CARLONI, Paola Regina; REIS, Fernando Figueiredo dos Santos. O trabalho enquanto possibilidade de inclusão: as contradições entre a adaptação para o mercado e a humanização pelo reconhecimento no trabalho. In; FREIRE, A. C.; ANDRADE, T. C.O. (Orgs.). Inclusão, Educação e Sociedade. Goiânia: Mundial Gráfica, p. 39-52, 2018.

CHAUÍ, Marilena. Escritos sobre a universidade. São Paulo: UNESP, 2001.

CROCHÍK, José Leon. Preconceito, indivíduo e cultura. 3. Ed. São Paulo: Casa do Psicólogo, 2006.

CROCHÍK, José Leon; Preconceito e Educação Inclusiva. Brasília: SDH/PR, p. 109123, 2011 a.

CROCHÍK, José Leon; CROCHÍK, Nicole. Teoria Crítica e Educação Inclusiva. In: CROCHÍK, José Leon (coordenador). Preconceito e Educação Inclusiva. Brasília: SDH/PR, p. 109-123, 2011b.

CROCHÍK, José Leon. Educação Inclusiva e Preconceito: Desafios para a prática pedagógica. In: MIRANDA, Theresinha Guimarães; FILHO, Teófilo Alves Galvão. (Orgs.). O professor e a educação inclusiva: formação, práticas e lugares. Salvador: EDUFBA, 2012.

GIROTO, Claudia Regina Mosca; POKER, Rosimar Bortolini; OMOTE, Sadao. Educação Especial, formação de professores e o uso das tecnologias de informação e comunicação: a construção de práticas pedagógicas inclusivas. In: As tecnologias nas práticas pedagógicas inclusivas.

GIROTO, Claudia Regina Mosca.; POKER, Rosimar Bortolini.; OMOTE, Sadao. (Orgs.). Marília: Oficina Universitária; São Paulo: Cultura Acadêmica, 2012.

FREITAS, Cesar Gomes de; DELOU, Cristina Maria; CASTRO, Helena Carla. Alunos com deficiência: investigação e análise das condições de atendimento de um Instituto Federal de Educação, Ciência e Tecnologia no Brasil. Revista Educação Especial, Santa Maria, v. 28, n. 53, p. 765- 778, set/dez, 2015. Disponível em: https://periodicos.ufsm.br/educacaoespecial/article/view/15747. Acesso: 10 maio. 2018. 
LANA, Z. M. O; CASTRO, F. G. A. S; MARQUES, S. M. F. Memória e Identidade docente de uma professora surda do Ensino Superior. Revista Educação Especial, Santa Maria, v. 29, n. 54, p. 69-82, jan./abr., 2016. Disponível em: https://periodicos.ufsm.br/educacaoespecial/article/view/17812. Acesso: 10 Jul. 2018.

LEITE, Lúcia Pereira; ACUNA, José Tadeu. Concepção de professores universitários sobre as condições de inclusão do aluno com deficiência no ensino superior. In: CONGRESSO BRASILEIRO DE EDUCAÇÃO ESPECIAL. VIII, 2018, São Carlos. Anais Eletrônicos. Local: Galoá, 2018. Disponivel em: file://C:/Users/B\%C3\%A1rbara/Downloads/galoa-proceedings--CBEE\%202018-93488.pdf. Acesso em: 11 jul. 2019.

LIMA, Marques de; MASSON, Leilyane O. A. O mal-estar na educação inclusiva no país da cordialidade. In: CAROLINI, P. R.; FREIRE, A. C.; ANDRADE, T. C.O. (Orgs). Inclusão, Educação e Sociedade. Goiânia: Mundial Gráfica, p. 53-68, 2018.

MARQUES, Carlos Alberto; MARQUES, Luciana Pacheco. Do universal ao múltiplo: os caminhos da inclusão. In: OLIVEIRA, Maria Rita Neto Sales; SOUSA, Luciana Freire. E. C. P. (Org.). Políticas educacionais, práticas escolares e alternativas de inclusão escolar. Rio de Janeiro: DP\&A, p. 237, 2003.

MAZZOTTA, Marcos José da Silveira. Educação Especial no Brasil: História e Políticas Públicas. 5 Ed. São Paulo: Cortez, 2005.

MENDES, Hernestina da Silva Fiaux.; BASTOS, Camen Célia Barradas Correia. Um estudo sobre a realidade da inclusão de pessoas com deficiência na educação superior no Paraná. Revista Educação Especial, Santa Maria, V. 29, n.54, p. 189202, jan./abr., 2016.2 Disponível em: https://periodicos.ufsm.br/educacaoespecial/article/view/17215. Acesso em: 9 jul. 2018.

NÓVOA, Antônio. Formação de professores e profissão docente. In: NÓVOA, Antônio (Coord.). Os professores e a sua formação. Lisboa: Dom Quixote, p. 25, 1995.

PANSANATO, L. T. E; RODRIGUES, L.; SILVA, C. E. Inclusão de estudante cego em curso de análise e desenvolvimento de sistemas de uma instituição pública de ensino superior: um estudo de caso. Revista Educação Especial, Santa Maria, v. 29, n. 55, p. 471-486, mai./ago., 2016. Disponível em: https://periodicos.ufsm.br/educacaoespecial/article/view/17106. Acesso em: 9 maio 2018.

SALES, Z. N; MOREIRA, R. M; COUTO, E.S. O convívio acadêmico: representações sociais de alunos com Necessidades Educacionais Especiais. Revista Educação Especial, Santa Maria, V. 29, n.55, p. 295-308, maio/ago., 2016. Disponível em: https://periodicos.ufsm.br/educacaoespecial/article/view/14275. Acesso em: 9 maio 2018. 
SASSAKI, Romeu Kazumi. Construindo uma sociedade para todos. Rio de Janeiro: WVA, 1997.

SAVIANI, Dermeval. Pedagogia histórico-crítica: primeiras aproximações. 11. Ed. rev. Campinas, SP: Autores Associados, 2011.

TRIVIÑOS, Augusto N. S. Introdução à pesquisa em ciências sociais: a pesquisa qualitativa em educação. São Paulo: Atlas, 1987.

UNESCO. Declaração mundial sobre educação para todos: satisfação das necessidades básicas de aprendizagem. Jomtien, 1990.

VALA, Jorge.; MONTEIRO, Maria. Benedita. (Eds.). Psicologia social. 9. Ed. Lisboa: Fundação Calouste Gulbenkian, 2002.

\section{Correspondência}

Bárbara Andressa Mendonça de Rocha Mesquita - Universidade Federal de Goiás. Av. Esperança, s/n - Chácaras de Recreio Samambaia. CEP: 74690-900. Goiânia, Goiás, Brasil.

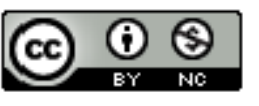

This work is licensed under a Creative Commons Attribution-NonCommercial 4.0 International (CC BY-NC 4.0) 